\title{
Gestão por processos na educação: a experiência do Programa Melhoria da Educação no Município ${ }^{1}$
}

Sonia Dias *

Tatiana Bello Djrdjrjan**

* Doutoranda em Educação (FE-USP), especialista em Política e Planejamento de Educação pela Vanderbit University. Atua em projetos na área de educação, especialmente em materiais de educação para professores e gestores públicos.

** Pós-graduanda em Gestão Pública pela Fundação Escola de Sociologia e Política de São Paulo. Atua em projetos de formação de educadores, gestores públicos e ativação de redes intersetoriais.
Resumo: Com base na experiência desenvolvida no Programa Melhoria da Educação do Município nos anos de 2011 e 2012, o artigo discute a implementação da gestão por processos como uma possibilidade de responder às necessidades da educação nos pequenos municípios brasileiros. Como conclusão, aponta-se que a adoção da gestão por processos pode contribuir para o aprimoramento da gestão municipal de educação em pequenos municípios e uma maior qualificação de equipes gestoras municipais.

PALAVRAS-ChAVE: Gestão educacional. Gestão municipal. Qualidade da educação.

1 O presente artigo se baseia na experiência retratada na publicação "Diálogos sobre a Gestão Municipal Processos na Educação", Cenpec/FIS, 2012. 


\section{INTRODUÇÃO}

O presente artigo apresenta a experiência desenvolvida no âmbito do Programa Melhoria da Educação do Município nos anos de 2011 e 2012, tendo como ponto de partida a gestão por processos como uma possibilidade de responder às necessidades da educação em pequenos municípios brasileiros.

No Brasil, conforme dados do Censo 2010, mais de 70\% dos municípios estão na categoria micro e pequeno porte, ou seja, possuem até 50 mil habitantes (IBGE, 2011). Assim como para os grandes centros urbanos, alcançar a educação pública de qualidade é um grande desafio também nos pequenos municípios.

Diferente das grandes cidades - onde muito se tem feito para melhorar a educação pública - as dificuldades nas cidades pequenas ainda precisam de maior atenção e enfrentamento, pois cada um desses 4.878 municípios conta com suas especificidades regionais e locais, e precisa também lidar com questões estruturais comuns na área: falta de profissionais especializados, existência de salas multisseriadas, dificuldades no processo de transporte escolar e limitada capacitação de professores. Soma-se a esses desafios, a formação de gestores de educação, pois cerca de $70 \%$ deles estão em posição de gestão pela primeira vez.

Para colaborar com o aprimoramento da gestão educacional nos municípios de micro e pequeno porte, foi criado o Programa Melhoria da Educação no Município, iniciativa da parceria entre a Fundação Itaú Social, o Fundo das Nações Unidas Para a Infância (Unicef) e o Centro de Estudos e Pesquisas em Educação, Cultura e Ação Comunitária (Cenpec), com apoio da União Nacional dos Dirigentes Municipais de Educação (Undime). O Programa tem como objetivo contribuir para a qualificação constante da gestão municipal da educação para garantir o acesso, permanência e aprendizagem na idade correta. Desde sua criação, em 1999, já atuou em dezoito estados, formando cerca de 3.500 gestores e técnicos, beneficiando mais de mil municípios, 32.373 escolas e 7.462 .051 alunos.

Em suas edições, o Programa concentrou-se na formação e aprimoramento profissional dos técnicos e gestores da educação e na construção de Planos de Educação das Secretarias Municipais, a partir de quatro eixos: avaliação diagnóstica, fórum de educação, intervenção na educação básica e acompanhamento e avaliação das ações planejadas, considerando a interligação entre essas ações como apresentado na figura 1 (CENPEC, 2009, p. 24). 


\section{Figura 1 - Planejamento e Gestão do Plano Educacional}

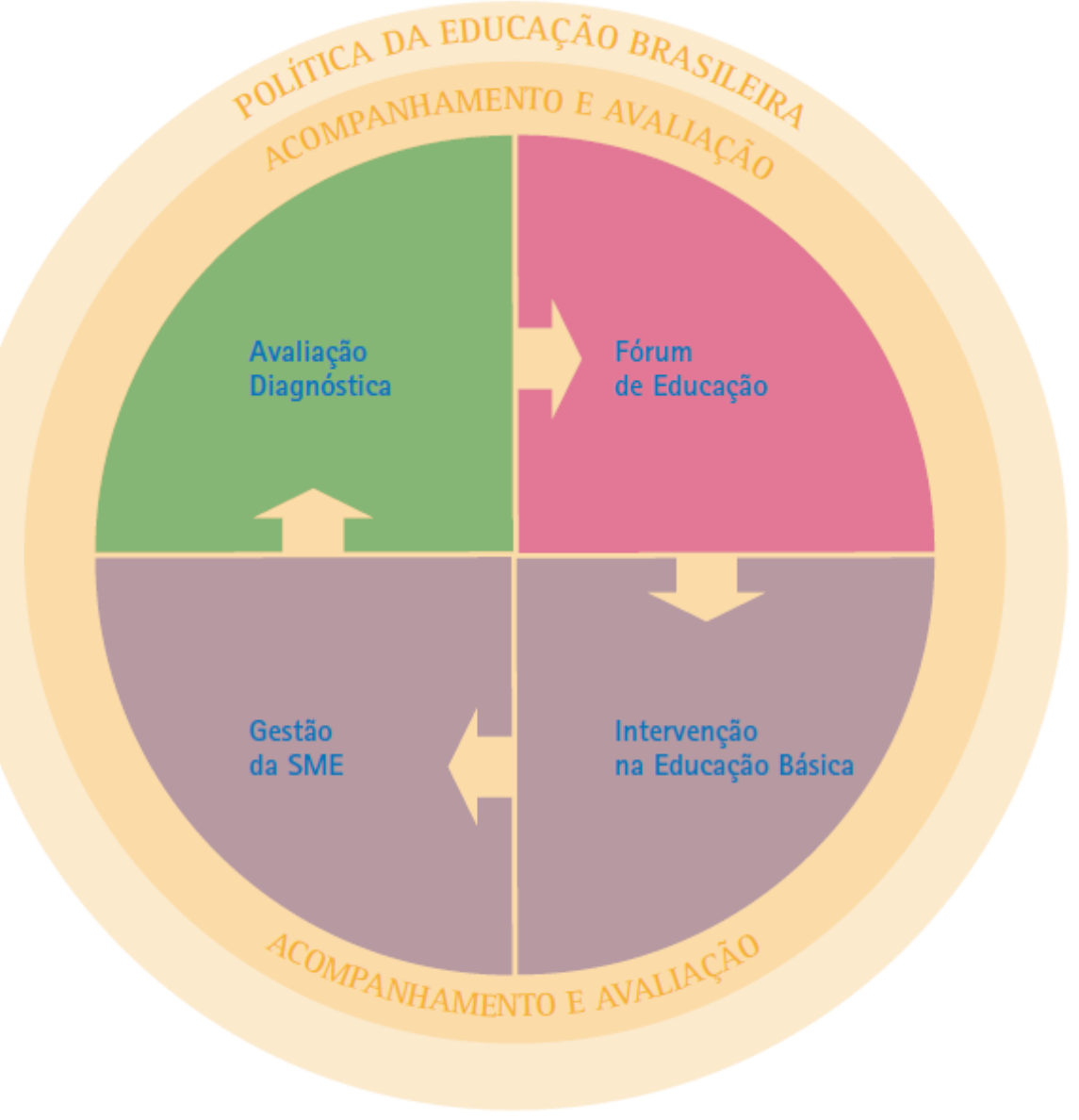

1 Elaboração da Avaliação Diagnóstica, um processo investigativo sobre a realidade educadora do municipio.

2 Constituição de um Fórum de Educação: espaço de articulação institucional de acompanhamento e avaliação da política de educação.

3 Formulação e implementação da Intervenção para a Educação Básica coerente com a Avaliação Diagnóstica, contendo a definição de princípios, metas, ações e mecanismos de gestão do Plano;

4 Desenvolvimento do acompanhamento e avaliação que perpassa todo o processo de elaboração e efetivação do Plano de Educação.

Fonte: CENPEC, 2009.

Nesse contexto, o Plano de Educação tem "um caráter reflexivo, organizador e articulador e não acontece em um percurso linear", sua implementação "depende da criação de mecanismos para sua gestão, processo que se inicia no interior da Secretaria de Educação, na análise de sua estrutura, organização e funcionamento (CENPEC, 2009, p. 25)". 
Uma avaliação do Programa Melhoria realizada em 2007 pela Fundação Itaú Social a partir dos indicadores educacionais dos municípios participantes demonstrou que

os resultados são positivos e estatisticamente significativos: o programa aumentou as taxas de aprovação e diminuiu as taxas de reprovação e de abandono em relação às taxas do grupo de controle, um e dois anos após o programa. Nos municípios que elaboraram plano

de ação e nos que tiveram formação direta, o programa teve impacto estatisticamente significativo sobre as taxas de aprovação e de abandono, um e dois anos após o programa

(FUNDAÇÃO ITAÚ SOCIAL, 2007, p. 5).

A metodologia do Programa também serviu como uma das inspirações para a formulação do Plano de Ações Articuladas (PAR) do MEC, criado em 2007, que pode ser preparado a partir de um conjunto de ferramentas e orientações que estados e municípios têm acesso para realizar um diagnóstico da realidade educacional local. 0 diagnóstico do PAR está estruturado em quatro grandes dimensões: 1- Gestão Educacional; 2- Formação de Professores e dos Profissionais de Serviço de Apoio Escolar; 3- Práticas Pedagógicas e Avaliação; 4 - Infraestrutura Física e Recursos Pedagógicos (MEC, 2012).

Em sua 11 â edição, realizada de 2010 a 2012, o Programa Melhoria em diálogo com o contexto macro da política educacional - maior autonomia dos municípios na condução da educação e fortalecimento do Plano Municipal de Educação como instrumento de planejamento e acesso a recurso - e na busca de aprimorar sua metodologia orientou suas ações a partir de dois desafios:

1. Como dar mais perenidade aos planos de educação que vinham sendo produzidos?

2. Como criar fluxos de gestão dinâmicos e potentes desde o órgão gestor da educação até a sala de aula para que a política educacional se efetive numa melhora de aprendizagem das crianças e adolescentes?

A partir desses questionamentos, o Programa concentrou sua atuação na experiência piloto, realizada no Paraná, iniciada com a construção do Plano Municipal de Educação com ênfase na participação social e, em uma segunda etapa, na sistematização e otimização de processos no órgão gestor da educação tendo a gestão por processos como eixo norteador.

O presente texto, apesar de não esgotar os diferentes aspectos envolvidos na experiência relacionada aos processos de gestão educacional, procura apresentá-la no âmbito da inter-relação da gestão educacional e a gestão por processos e contribuir com referências e inspiração no sentido de potencializar e dar mais efetividade à gestão municipal da educação. 


\title{
A EXPERIÊNCIA DE GESTÃO POR PROCESSOS NA EDUCAÇÃO
}

A opção de atuar na implantação da gestão por processos no órgão gestor da educação considera que essa metodologia de trabalho favorece a organização e a articulação das diferentes ações necessárias para efetivar uma educação qualificada no município. É preciso destacar que todas as ações da gestão tiveram como base as concepções orientadoras da política educacional nos marcos legais existentes.

A gestão por processos aplicada à educação apresenta a possibilidade de concretizar uma alteração na forma de organizar o trabalho, de forma que este se torne mais horizontal. Isso acontece porque a gestão por processos se baseia nas ações a serem realizadas e não na estrutura hierárquica. Isso cria mais comprometimento, pois favorece a integração e envolve todos os profissionais com o resultado final, já que há clareza dos motivos nos quais se baseiam as ações, bem como para quem e como elas devem ser realizadas. Esse direcionamento faz com que as equipes adquiram capacidade crítica, de planejamento e de trabalho coletivo e assim possam aprimorar suas atividades.

\begin{abstract}
A gestão por processos organizacionais difere da gestão por funções tradicional em pelo menos três pontos: emprega objetivos externos; os empregados e recursos são agrupados para produzir um trabalho completo; e a informação segue diretamente para onde é necessária, sem o filtro da hierarquia. (STEWART², 1992 apud GONÇALVES, 2000a, p.16)
\end{abstract}

Outro ponto importante para a implantação da gestão por processos é a sua sintonia com os objetivos e metodologia do Programa Melhoria na medida em que tem como princípio a melhoria contínua que pressupõe uma revisão constante das formas de fazer para aprimorar fluxos e resultados.

Para a educação, implementar a gestão por processos é uma maneira de aprimorar a ação, visualizando os encadeamentos e as responsabilidades associadas às suas atividades. É uma forma de gestão que leva o profissional a se responsabilizar não apenas pelo que faz, de forma compartimentada e burocratizada, e sim favorecer a visão de conjunto desde os objetivos da política educacional até o seu resultado final - a aprendizagem dos alunos na idade correta.

STEWART, T. A. The search for the organization of tomorrow Are you flat, lean, and ready for a bold new look? Try high-performance teams, redesigned work, and unbridled information. Fortune Magazine, Chicago, 18 Mai. 1992. Disponível em: 〈http://money. cnn.com/magazines/fortune/fortune_archive/1992/05/18/76425/〉. Acesso em: 12 Nov. 2012. 
A organização orientada por processos pressupõe que as pessoas trabalhem de forma diferente. Em lugar do trabalho individual e voltado a tarefas, a organização por processos valoriza o trabalho em equipe, a cooperação, a responsabilidade individual e a vontade de fazer um trabalho melhor. Ela projeta e mensura cuidadosamente seus processos e faz com que todos os funcionários entendam e se responsabilizem por eles, possibilitando o desenvolvimento de um sentimento de "propriedade do processo". As pessoas cumprem tarefas, mas têm uma visão mais ampla e pensam a respeito dos processos. (GONÇALVES, 2000b, p. 11)

\section{ETAPAS DA IMPLANTAÇÃO DA GESTÃO POR PROCESSOS}

\section{IDENTIFICAÇÃO, CONSULTA E REDESENHO DOS PROCESSOS}

A metodologia empregada nesse trabalho foi inicialmente estabelecer os processos que seriam objetos de análise, identificar as ações que os municípios já faziam nesses processos, sistematizar as informações recebidas e redesenhar os processos de forma aprimorada para promover a sua implantação. Essa ação é bastante valiosa na medida em que

[...] é virtualmente impossível mudar de uma organização por tarefas para uma organização orientada por processos sem um claro entendimento do que exatamente faz a empresa funcionar bem e ter ritmo [...]. Um quadro claro dessa situação deve servir de ponto de partida para todos os subseqüentes alinhamentos de pessoas e processos

(GONÇALVES, 2000b, p. 9).

Numa primeira etapa - que ocorreu em 2011, houve o estabelecimento dos processos administrativos/ financeiros e pedagógicos envolvidos na gestão educacional municipal. Essa ação se deu pela identificação de quais ações referentes ao suporte à educação, administrativas e pedagógicas seriam objeto de estudo.

No âmbito dos processos administrativo/financeiros foram identificados seis diferentes grupos. São eles:

1. Gestão do suporte a educação - merenda, transporte escolar, matrícula, uniforme e atribuição de classes e aulas.

2. Gestão orçamentária e financeira.

3. Gestão de materiais e serviços.

4. Gestão do patrimônio.

5. Gestão de pessoas.

6. Gestão da comunicação. 
Quanto aos processos relacionados à gestão pedagógica, foram consolidados dois grupos, um referente ao Projeto Político Pedagógico das unidades escolares, com o intuito de trazer para o centro da política pública esse importante instrumento de autonomia da escola, e o outro baseado na relação da gestão educacional com a prática pedagógica e a consequente aprendizagem. São eles:

1. Gestão do Projeto Político Pedagógico;

2. Gestão da avaliação do ensino e aprendizagem.

Cabe ressaltar que a gestão educacional foi considerada a partir de duas dimensões - administrativo/financeira e pedagógica - entendendo que apesar das suas especificidades, esses eixos estão intimamente interligados e, portanto, não podem ser efetivados de forma isolada. Assim, a identificação discriminada dos processos nos dois eixos serve para visualizar tanto o seu detalhamento quanto a sua interface.

No caso da gestão pedagógica é preciso destacar que, como esta compreende um grande número de processos de alta complexidade e abrangência, a opção nesse trabalho foi aprofundar o entendimento sobre os dois processos que julgamos serem os mais pertinentes ao apoio devido pelo órgão gestor da educação às escolas - o Projeto Político Pedagógico e a avaliação do ensino e aprendizagem.

Após essa identificação, foi realizada a definição do roteiro para a coleta de dados dos processos administrativo/financeiros e pedagógicos com a elaboração de um documento composto por um questionário a ser respondido para o mapeamento das ações já realizadas pelos municípios nesses âmbitos.

Com a sistematização das respostas e levando em conta o contexto dos municípios e o princípio da melhoria contínua, os processos foram redesenhados. A proposta do redesenho procurou incorporar as melhores práticas existentes e apresentar os processos envolvidos de forma a atender e aprimorar a gestão da educação para municípios do mesmo porte.

Durante essas ações, ainda foram realizadas duas oficinas junto aos municípios com o intuito de discutir e refletir sobre o conceito da gestão por processos e suas possibilidades de inovação nas rotinas de trabalho dos participantes, socializar a produção sobre o redesenho dos processos, bem como propiciar o registro e a reflexão de situações vivenciadas pelos municípios nos temas dos processos.

Após esse trabalho de identificação, experimentação, acompanhamento e análise, os processos envolvidos na gestão educacional foram sistematizados, 
conforme descrito na tabela 1:

Tabela 1 - Organização dos processos envolvidos na gestão educacional

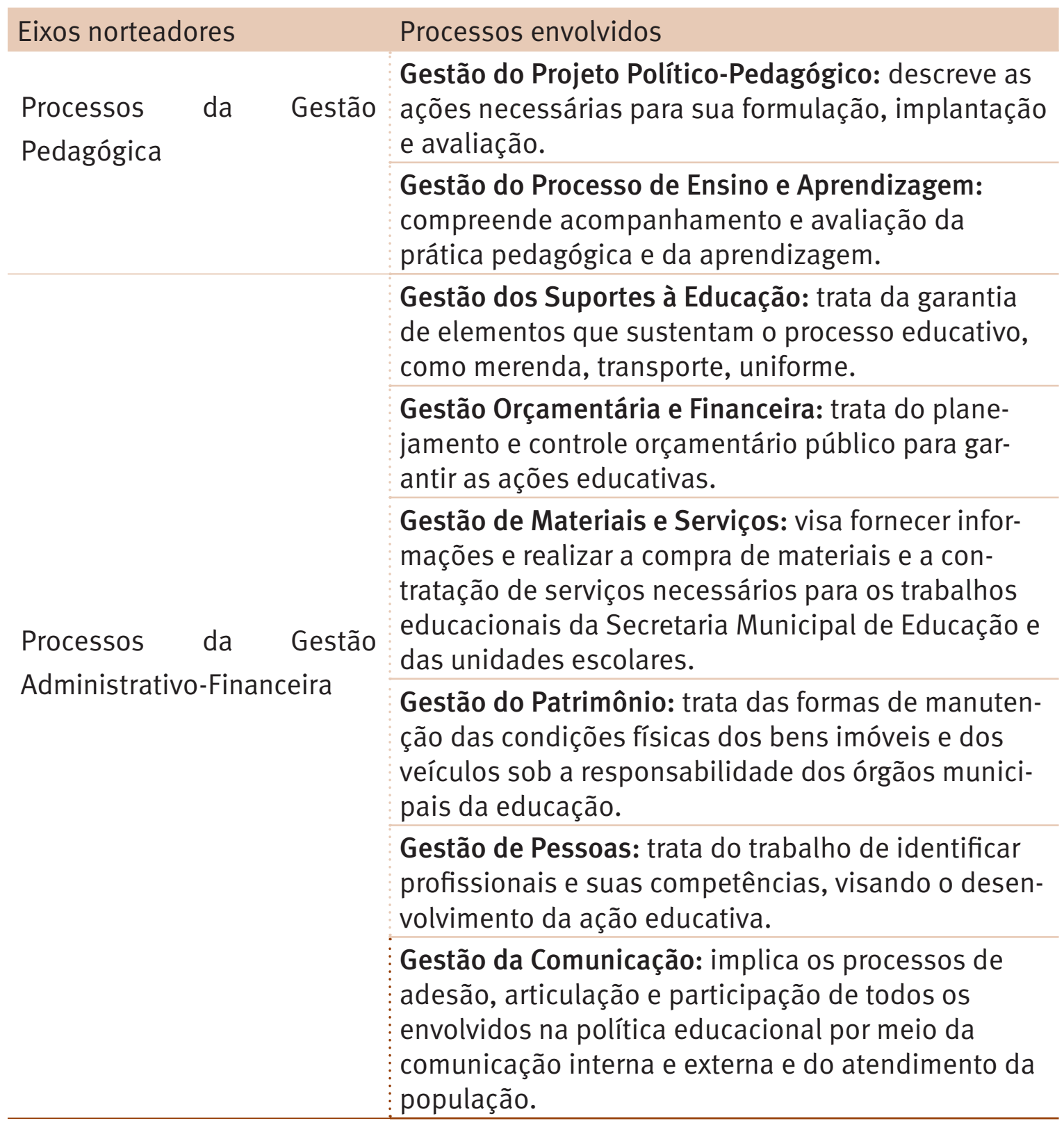

A implantação dos processos foi iniciada em 2012 com a análise dos principais desafios da gestão educacional, identificados a partir do Plano Municipal de Educação (PME) e do Plano Anual de Trabalho do órgão gestor da educação do município, já existente nas cidades participantes. Nessa etapa, os municípios fizeram as escolhas de dois processos que mais se adequavam às suas necessidades, um relacionado à gestão pedagógica e outro à gestão administrativo-financeira, como forma de propiciar uma vivência mais diversificada, conforme a tabela 2: 
Tabela 2 - Processos da Gestão Escolar e Processos da Gestão Administrativa/Financeiro por município.

\begin{tabular}{|c|c|c|}
\hline Municípios & Processos da Gestão Escolar & $\begin{array}{l}\text { Processos da Gestão Administrativa / } \\
\text { Financeiro }\end{array}$ \\
\hline Boa Ventura São Roque & $\begin{array}{l}\text { Gestão do Processo de } \\
\text { Ensino e Aprendizagem }\end{array}$ & $\begin{array}{l}\text { Gestão do suporte à Educação - } \\
\text { Gestão do Transporte Escolar }\end{array}$ \\
\hline Cândido de Abreu & $\begin{array}{l}\text { Gestão do Processo de } \\
\text { Ensino e Aprendizagem }\end{array}$ & $\begin{array}{l}\text { Gestão de Pessoas - Realizar formação } \\
\text { continuada }\end{array}$ \\
\hline Iretama & $\begin{array}{l}\text { Gestão do Processo de } \\
\text { Ensino e Aprendizagem }\end{array}$ & $\begin{array}{l}\text { Gestão de Pessoas - Realizar formação } \\
\text { continuada }\end{array}$ \\
\hline Manoel Ribas & $\begin{array}{l}\text { Gestão do Processo de } \\
\text { Ensino e Aprendizagem }\end{array}$ & $\begin{array}{l}\text { Gestão de Pessoas - Realizar formação } \\
\text { continuada }\end{array}$ \\
\hline Nova Tebas & $\begin{array}{l}\text { Gestão do Processo de } \\
\text { Projeto Político Pedagógico }\end{array}$ & $\begin{array}{l}\text { Gestão de Pessoas - Realizar formação } \\
\text { continuada }\end{array}$ \\
\hline Palmital & $\begin{array}{l}\text { Gestão do Processo de } \\
\text { Projeto Político Pedagógico }\end{array}$ & $\begin{array}{l}\text { Gestão do suporte à Educação - } \\
\text { Gestão do Transporte Escolar }\end{array}$ \\
\hline Pitanga & $\begin{array}{l}\text { Gestão do Processo de } \\
\text { Ensino e Aprendizagem }\end{array}$ & $\begin{array}{l}\text { Gestão de Pessoas - Avaliar o } \\
\text { desempenho dos servidores }\end{array}$ \\
\hline Rio Branco do Ivaí & $\begin{array}{l}\text { Gestão do Processo de } \\
\text { Projeto Político Pedagógico }\end{array}$ & Gestão do Patrimônio - Planejar Obras \\
\hline Roncador & $\begin{array}{l}\text { Gestão do Processo de } \\
\text { Ensino e Aprendizagem }\end{array}$ & $\begin{array}{l}\text { Gestão do Patrimônio - Realizar } \\
\text { manutenção em prédio }\end{array}$ \\
\hline Rosário do Ivaí & $\begin{array}{l}\text { Gestão do Processo de } \\
\text { Ensino e Aprendizagem }\end{array}$ & $\begin{array}{l}\text { Gestão do Suporte à Educação - } \\
\text { Gestão do Transporte Escolar }\end{array}$ \\
\hline
\end{tabular}

O primeiro passo para preparar a gestão por processos foi a elaboração de um Plano de Implantação, com a identificação e planejamento das atividades preliminares - que deveriam anteceder as próprias ações dos processos aprimorados e ser relacionadas de acordo com as condições e necessidades de cada localidade e das áreas envolvidas. Para auxiliar esse levantamento e análise, foram consideradas algumas ações preliminares, tanto no âmbito do gerenciamento para a mudança no órgão gestor da educação quanto do ponto de vista da execução dos processos aprimorados. Essas ações são descritas em linhas gerais na tabela 3: 
Tabela 3 - Ações preliminares.

Ações preliminares observadas durante o processo de implantação da gestão

- Definir a equipe responsável pela elaboração do plano de implantação.

- Identificar as atividades preliminares.

Gerenciamento do esforço de mudança do órgão gestor da educação

- Escolher a metodologia de acompanhamento.

- Elaborar o Plano de Implantação.

- Definir o cronograma das atividades preliminares.

- Elaborar a matriz de responsabilidades pelo acompanhamento e execução do plano de implantação.

- Articular com outros órgãos ou secretarias.

- Alterar legislação, se necessário.

- Desenvolver formulários, documentos normativos e/ou instrumentais.

Execução das mudanças nos processos aprimorados
- Adequar ou desenvolver sistemas informatizados.

- Capacitar profissionais.

- Contratar serviços e/ou pessoas.

- Adquirir materiais e mobilizar os recursos necessários para a mudança.

2. AÇÕES PRELIMINARES PARA A IMPLANTAÇÃO DOS PROCESSOS

Durante a etapa preliminar da implantação da gestão por processos, boa parte dos desafios encontrados foram aqueles relacionados à realização das atividades, responsabilização e recursos, entre outras questões. Um exemplo disso ocorreu com o município de Boa Ventura de São Roque que, ao experimentar o processo relacionado à Gestão de Transporte identificou ser necessária a criação de um instrumental para fazer a pesquisa de satisfação com os pais dos alunos sobre a qualidade do serviço. Outros fatores também podem influenciar na implantação dos processos, o quadro 1 apresenta um conjunto de questões que podem ser norteadoras para as ações de aprimoramento dos processos no órgão gestor da educação. 
Quadro 1: Questões a serem consideradas para a implantação da gestão por processos:

- Que atividades devem acontecer para que o processo aprimorado se concretize de acordo com o novo desenho?

- As ações do processo já existentes podem ser adaptadas ou será preciso criar novas?

- Quem será responsável e/ou desempenhará cada atividade?

- Será necessário contratar alguém ou modificar a rotina de trabalho de algum dos envolvidos?

- Quais informações/recursos serão necessários?

- Será preciso adquirir algum bem/equipamento novo ou adequar os existentes?

- Quais os gastos envolvidos nesse processo?

- Quais as informações utilizadas ou geradas pelos processos aprimorados?

- É necessário alterar ou desenvolver novos formulários, documentos normativos e/ou instrumentais?

- Quais as regras/normas que dão sustentação legal aos trabalhos que serão desenvolvidos?

- Há necessidade de adequação dessa legislação?

- Será necessário ou importante o envolvimento de outras áreas, secretarias ou municípios?

- Quais as estratégias para promover esse envolvimento?

Fonte: Cenpec; FUNDAÇÃO ITAÚ SOCIAL, 2012, p. 37.

\section{Plano de Implantação}

Depois das ações preliminares, o passo seguinte foi a identificação das áreas do órgão gestor da educação em que seriam implementadas as mudanças, dos profissionais envolvidos e das ações preliminares necessárias com previsão de responsáveis e prazos, além do controle das ações. O resultado desse esforço foi a construção do Plano de Implantação dos processos aprimorados.

Todo o processo de implantação - desde sua concepção, desenho e ações - contou com acompanhamento técnico realizado por meio de encontros presenciais, visitas técnicas e uma assessoria feita pelos técnicos do Programa Melhoria junto às equipes e gestores dos municípios. Para complementar as atividades presenciais, também foi realizado acompanhamento à distância por meio de contatos telefônicos, e-mails e conversas com o uso de recursos tecnológicos, como o Skype. 


\section{IMPLANTAÇÃO DOS PROCESSOS DA GESTÃO PEDAGÓGICA}

Na implantação do processo de Gestão do Projeto Político Pedagógico (PPP), o principal desafio enfrentado pelos municípios - Roncador, Iretama e Nova Tebas - foi desenvolver dispositivos que garantissem que as orientações para a formulação do Projeto Político Pedagógico (PPP) estivessem em sintonia com as diretrizes da política educacional do município, além de criar condições para que essa elaboração se desse em cada uma das escolas do município, considerando seus contextos e peculiaridades.

A equipe do órgão gestor da educação de Roncador procurou realizar uma ampla discussão com a comunidade escolar, com visitas às escolas e reuniões regulares com professores e coordenadores pedagógicos, para promover a revisão dos PPPs que estavam sendo utilizados pelas equipes pedagógicas das escolas. A partir dessas ações, cada escola iniciou uma pesquisa por meio de questionários com a comunidade escolar, envolvendo professores, funcionários, alunos e pais. A partir dessa consulta, as escolas elaboraram um diagnóstico do seu contexto, que foi analisado e discutido em reunião do Conselho de Escola e forneceu a base para a construção das metas que seriam incorporadas ao PPP.

No caso do município de Iretama, a equipe técnica do órgão gestor da educação avalia que a implantação da gestão por processos aplicada à formulação dos PPPs teve como consequência uma maior organização do trabalho e auxiliou a sistematizar as atividades do órgão gestor da educação no município. A equipe participante do Programa Melhoria em Manoel Ribas avalia que 0 fato de ter realizado uma ampla consulta à comunidade escolar redundou na percepção de valorização da contribuição principalmente pelos professores de áreas rurais, fato que se refletiu na melhor consonância das atividades propostas no PPP e no contexto local.

Éimportante destacarque na experiência dos municípios, mesmo considerando que o processo de elaboração do PPP esteja mais relacionado às atividades internas à escola e, portanto, marca de sua autonomia, o investimento na manutenção de canais de comunicação e interlocução permanentes entre as equipes pedagógica do órgão gestor da educação e as unidades escolares teve papel fundamental no apoio, acompanhamento e na efetivação do PPPs.

Dessa forma, a implantação desse processo trouxe ainda mais clareza da importância do PPP como instrumento da política educacional e, portanto, refletido e construído a partir das diretrizes contidas no Plano Municipal de 
Educação, ou seja, considerando as potencialidades e conhecimentos locais.

Quanto ao processo de gestão da avaliação do ensino e aprendizagem, houve inicialmente por parte das equipes técnicas do órgão gestor dos municípios que o implementaram a preocupação de como identificar as diferentes ações já existentes, a organização das atividades e a elaboração de indicadores avaliativos. Aos poucos essa dificuldade foi diminuindo com a realização dos processos redesenhados, o acompanhamento da equipe técnica do Programa Melhoria e a percepção de resultados positivos que encorajaram a continuidade do investimento feito.

Pode-se observar que, durante o trabalho, algumas das atividades realizadas foram comuns a todos os municípios, como o planejamento de visitas às escolas pelas equipes dos municípios com o intuito de assessorar o trabalho educativo na sala de aula, a elaboração de instrumentais para a autoavaliação dos professores e a inclusão de reunião de avaliação em cada escola no final do ano letivo.

Essas ações foram bem recebidas pela rede e tiveram como principal objetivo aproximar as equipes pedagógicas do órgão gestor da educação das escolas, bem como assegurar a coleta de informações para compor o mosaico da avaliação geral da aprendizagem, que conta também com dados da avaliação externa.

No que se refere ao uso dos dados da avaliação externa, as equipes dos municípios que contam com uma avaliação na rede (Nova Tebas e Boa Ventura de São Roque) afirmam ter percebido que os dados de seus exames em muito complementam os das avaliações de larga escala realizadas em âmbito estadual e federal, pois além de trazerem os componentes dos Parâmetros Curriculares Nacionais, possuem informações mais contextualizadas da sua rede escolar, região e de seus alunos.

Os municípios consideraram que era necessário reformular os Planos de Ensino, a partir da constatação de que estes tinham um caráter mais burocrático que pedagógico ou estavam desatualizados. Esse movimento, apesar de contar com algumas resistências no ambiente educacional, trouxe avanços extremamente relevantes que puderam ser percebidos no acompanhamento realizado pelo programa:

1. Aumento do pessoal no pedagógico.

2. Sistematização e uso dos resultados da sondagem.

3. Existência, a partir dessa experimentação, de uma equipe multidisciplinar. 
A elaboração de instrumentais ou ainda a revisão dos já existentes e a publicização dos resultados foram importantes estratégias utilizadas pelos municípios para aprimorar o acompanhamento da aprendizagem dos alunos e, além de causar um maior envolvimento entre as equipes técnicas e a comunidade escolar no processo educativo, contribuíram para maior transparência e controle social.

Um exemplo disso foi a iniciativa da equipe técnica de Rio Branco do Ivaí, que realizou reuniões pedagógicas para, em conjunto com coordenadores pedagógicos e professores, elaborar os instrumentais para o diagnóstico inicial das turmas, que possibilita a identificação do nível de aprendizagem de cada aluno relacionando-o ao plano curricular da série/ano e aos resultados esperados de rendimento escolar.

No município de Pitanga, a equipe técnica reconheceu alguns desafios como o engajamento da rede para a proposta e potencialidades e a necessidade de promover a ampliação do olhar a partir do registro, sistematização e reorganização do acompanhamento escolar. Entre as questões apontadas pelas equipes técnicas dos municípios é que, em geral, não há uma cultura de acompanhamento pedagógico da escola por conta do hiato entre o órgão gestor e a escola. E, no caso dos municípios de pequeno porte, há ainda a dificuldade para a realização de reuniões periódicas em municípios de grande extensão territorial.

De forma geral, as equipes técnicas dos municípios reconheceram que o trabalho realizado diminuiu a distância entre o órgão gestor da educação e as escolas, além de propiciar uma possibilidade de reflexão e planejamento coletivo para as ações de avaliação do processo de ensino e aprendizagem, o que promoveu um envolvimento maior de todos e aprimorou a organização do trabalho do órgão gestor de educação.

\section{IMPLANTAÇÃO DOS PROCESSOS DA GESTÃO ADMINISTRATIVA E FINANCEIRA}

Quanto à implantação dos processos administrativo/financeiros, apesar do reconhecimento por todos do papel determinante que o bom andamento desses processos traz para o pleno acesso, permanência e qualidade da educação no município, a sua implantação apresentou desafios diferenciados em relação à gestão pedagógica.

Pode-se dizer que isso ocorreu tanto por parte da equipe do Programa Melhoria quanto das equipes técnicas do órgão gestor. Essa situação pode estar 
relacionada a diversas questões, como: a maior parte dos técnicos tem mais familiaridade com temas da área pedagógica e a percepção de que apesar de sua importância os processos administrativo/financeiros de alguma maneira subtraem um tempo que poderia ser dedicado ao pedagógico.

Por conta desses fatores, em alguns casos as equipes dos municípios utilizaram os processos redesenhados para a plataforma do PAR ou adaptaram os processos redesenhados em algumas ações, mas nem todos os municípios realizaram por completo a implantação dos processos dessa área ou concentraram seus esforços nos processos da gestão pedagógica.

$\mathrm{Na}$ implantação dos processos relativos ao transporte escolar, as equipes técnicas apontaram diversas dificuldades para contratar empresas. Essa resistência das empresas de maneira geral estava relacionada ao fato de as rotas escolares apresentarem baixa demanda e estarem em regiões onde as estradas costumam ser precárias e costumam ser afetadas por enchentes. Esses fatores tendem a desestimular os empresários do setor e fazem com que muitas vezes não se consiga realizar a contratação de transporte escolar, trazendo impactos diretos para o processo de ensino e aprendizagem.

Outro desafio para o transporte escolar está nas distâncias a serem percorridas ou o número de linhas necessárias, pois muitas vezes os municípios possuem uma extensão territorial razoável e a população rural está distribuída de maneira dispersa. Este é caso do município de Palmital, onde o transporte escolar precisa ser realizado por 38 linhas (próprias e terceirizadas) que percorrem diariamente 2.614 quilômetros e deslocam cerca de 1.800 alunos.

De maneira geral para os municípios, a implantação do processo de transporte escolar tornou possível planejar a pesquisa de satisfação do serviço a ser respondida pelos pais dos alunos, bem como incorporar uma lógica de avaliação do transporte escolar da rede como um todo e não somente de algumas linhas.

No caso da implantação do processo de manutenção de prédios, a equipe técnica do município apontou que era preciso conhecer esse processo de maneira aprofundada para que a atividade não se tornasse um ato mecânico ou burocrático; também era necessário organizar as tarefas envolvidas em sua realização com um passo a passo e, principalmente, atentar para a formulação dos indicadores que seriam utilizados para a avaliação das ações. Como afirma a gestora do município de Roncador: 
O processo de gestão de uma secretaria do porte de Roncador é diferente do exigido em grandes cidades. Aqui todos se conhecem; quando se precisa de algo basta telefonar. Não há necessidade de burocracia. Mesmo assim a participação no Programa Melhoria deu amparo para detalhar o que precisa ser feito e melhorou a organização dos trabalhos na secretaria (CENPEC, 2012, p. 160).

Esse trabalho ainda possibilitou uma maior organização do órgão gestor da educação, inclusive no sentido de refletir sobre a importância dos espaços para a proposta educativa, e foi um importante dispositivo para repensar e aperfeiçoar a articulação com outros órgãos da prefeitura:

Nesse sentido, vale destacar que os princípios utilizados pela gestão por processos também podem ser utilizados em outros procedimentos, como foi experimentado por Roncador, município que utilizou os parâmetros desses processos para o preenchimento do instrumental do PAR - Plano de Ações Articuladas do MEC (CENPEC, 2012, p. 165).

Para concretizar os processos de formação continuada, os municípios de Manoel Ribas, Iretama, Nova Tebas e Cândido de Abreu optaram por implantar o processo de formação continuada por meio de diferentes estratégias, tais como a participação de profissionais da própria rede ou a contratação de profissionais externos. Segundo uma das profissionais do órgão gestor de Manoel Ribas

Tínhamos formadores que vinham de fora, além disso, gerar mais gasto, eles em geral não conheciam nossa realidade. Decidiu-se, então, fazer um programa de capacitação contando com a participação de professores da própria rede (CENPEC, 2012:172).

\section{CONCLUSÃO}

A experiência vivenciada no âmbito do Programa Melhoria na implantação dos processos educacionais aponta para a existência de um espaço de inovação no sentido de aprimorar a gestão municipal de educação em pequenos municípios. A partir das ações realizadas, pode-se afirmar que a adoção da gestão por processos teve impacto positivo na educação dos municípios e nas atividades dos órgãos gestores da educação, seja na avaliação da aprendizagem, na forma de elaborar os planos educacionais e nas ações de suporte educacional.

As aprendizagens e desafios enfrentados durante a implantação podem também ter um papel indutor de ações de aprimoramento para outros municípios, na medida em que ao serem discutidas e analisadas estimulam o desenvolvimento de espaços de intercâmbio de experiências e saberes, ao mesmo tempo em que potencializam as ações a serem realizadas. 
Durante os encontros de acompanhamento um dos problemas apontados de forma recorrente era a realização de reuniões regulares, provocado geralmente pelo número de profissionais nas equipes e a grande quantidade de atividades a serem realizadas, o que reduz bastante o tempo de trabalho comum. A partir da experiência da implantação da gestão por processos, as equipes técnicas dos municípios apontam que entre os resultados se destacam um aumento nas ações de sistematização e organização do trabalho. Isso se refletiu em uma intensificação e otimização das reuniões realizadas, com registros que oferecem a possibilidade de avaliação e acompanhamento das decisões deliberadas.

Agestão por processos também se refletiu num acompanhamento mais próximo das escolas pelo órgão gestor da educação, com a realização de visitas mais regulares e no compartilhamento de ações e decisões da escola. Essa mudança pode estar relacionada ao fato de que a sistematização dos processos tornou mais clara o dimensionamento dos papeis e responsabilidades entre escola e órgão central e ajudou a administrar melhor as ações necessárias de cada uma das partes e como estas atividades devem ser realizadas.

Outro fator apontado é a potencialização do esforço dispendido e das atividades realizadas pelo órgão gestor. Isso possibilitou a construção de planos de implantação por processos que incorporassem a contribuição e as necessidades dos diferentes atores envolvidos na comunidade escolar.

Cabe ainda destacar entre os fatores positivos resultantes da vivência da gestão por processos na educação, é o trabalho das equipes técnicas em conjunto com seus gestores que possibilitou a participação e decisão durante todas as etapas - desde a identificação das ações e o redesenho até a implantação dos processos aprimorados. Essa participação pode estar associada à percepção dos profissionais de que esses processos correspondem de forma bastante acurada ao contexto e necessidades do município.

A partir da experiência foram elaborados os quadros 2 e 3, que procuram sintetizar os principais aprendizados e os desafios enfrentados pelos municípios durante o processo de implantação da gestão por processos (CENPEC; FUNDAÇÃO ITAÚ SOCIAL, 2012, p. 33). 
Quadro 2: Aprendizados.

- Potencializar a integração entre as equipes do órgão gestor da educação e as equipes com as escolas.

- Realizar o trabalho de forma mais articulada, intensificando o alinhamento e envolvimento entre as equipes.

- Aumento do acompanhamento pedagógico junto às escolas.

- Participação em ações com outras secretarias.

- Formular instrumentos a partir de uma análise mais detalhada dos instrumentos produzidos.

- Maior aprofundamento teórico por meio de grupos de estudos e reuniões mais sistemáticas.

Quadro 3: Desafios.

- Instaurar uma rotina de reuniões periódicas da equipe.

- Ampliar a qualificação da equipe frente às novas demandas de trabalho de forma a garantir a qualidade desejada.

- Elaborar os instrumentos: avaliação e acompanhamento do aluno, autoavaliação dos professores, autoavaliação da equipe gestora, etc.

- Planejar e organizar o trabalho.

- Registrar e sistematizar as ações.

- Formular os indicadores de acompanhamento e execução.

Ainda é preciso apontar que a gestão educacional municipal é um fenômeno de alta complexidade, que envolve também fatores relacionados ao contexto mais amplo das políticas públicas educacionais, seja no âmbito federal e estadual, como aponta Luck e Parente:

A descentralização da educação em sistemas federativos, como é o caso do Brasil, embora complexa, caracteriza-se pela flexibilidade e pelas diferentes relações que vêm sendo estabelecidas entre a União e as unidades subnacionais, que compreendem os estados e os municípios. [...] a descentralização educacional não é um processo homogêneo $e$ praticado em uma única direção. Ela responde à lógica da organização federativa, no sentido de: a) ordenar responsabilidades e competências nos planos administrativo e financeiro aos entes federativos; b) instituir processos desconcentrados de administrações financeira, administrativa e pedagógica; e c) instaurar a gestão democrática da escola, em cumprimento a preceito constitucional, cuja regulação maior encontra-se na nova Lei de Diretrizes e Bases da Educação Nacional (LDB/1996), institucionalizando a escola autônoma. (LÜCK; PARENTE, 1999, p. 4)

Outro resultado apontado pelas equipes, que pode estar relacionado não apenas com a gestão por processos, mas também com a metodologia 
colaborativa do Programa Melhoria, está a flagrante necessidade de se ampliar as possibilidades de articulação entre municípios de uma mesma região, considerando que possuem diversas características e desafios comuns, que podem ser enfrentados por meio de parceiras e na busca conjunta de soluções.

Entre as dificuldades, a mais recorrente nessa experiência foi a necessidade e ao mesmo tempo a dificuldade para a realização de ações articuladas entre secretarias. Observou-se durante a experiência de implantação da gestão por processos que houve pouca participação nos encontros de acompanhamento de profissionais de outras secretarias. Isso ocorreu mesmo em atividades que envolviam outras áreas como a administrativa e financeira. Pode-se considerar que a dificuldade de realização de ações articuladas entre secretarias parece estar relacionada a uma cultura amplamente difundida de segmentação entre as secretarias, o que tende a levar as equipes ao isolamento e dificultar a visualização das possibilidades de compartilhamento e de que a realização em conjunto e articulada entre as secretarias potencializa e fortalece a todos.

Em relação à intersetorialidade, é preciso destacar que esse é o grande desafio da gestão pública democrática, pois apesar de se falar muito nessa questão, ainda é difícil conceber estratégias e dispositivos orgânicos para que essa articulação seja facilitada, sendo necessária a costura das políticas interrelacionadas por meio de ações e práticas e com foco no atendimento integral das necessidades da população. Uma das participantes do Programa, técnica Secretaria de Educação de Boa Ventura de São Roque, destaca:

O detalhamento e a organização que aprendemos, aprimorou o trabalho que a gente já fazia, mas que até então mantinha só na cabeça. Conseguimos levar as atividades para professores, alunos, e mobilizar todos, e queremos levar à frente. Essa sistematização se refletiu em uma maior interação da secretaria. Agora est'amos mais envolvidos no todo, cada um contando com a ajuda do outro. Assim a secretaria trabalha como um todo. Todos juntos. (CENPEC; FUNDAÇÃO ITAÚ SOCIAL, 2012, p. 34)

Nesse sentido, entendemos que a experiência vivenciada no âmbito do Programa Melhoria da Educação no Município nos permite afirmar que a adoção da gestão por processos em muito pode contribuir para a demanda crescente de equipes gestoras dos municípios, no sentido de possibilitar maior qualificação e fazer com que estejam mais preparadas para lidar com questões que exigem maior aprofundamento, abrangência e visão integrada das políticas educacionais. 


\section{Management Process in education: the experience of the Education Improvement Program in the Municipality}

Abstract: Based on the experience developed in the Education Improvement Program in the Municipality in the years 2011 and 2012, this paper discusses the implementation of management process as an opportunity to respond to the needs of education in small municipalities. In conclusion, it points to that the adoption of management process can contribute to the improvement of municipal education management in small municipalities and a higher qualification of municipal management teams.

Keywords: Educational management. Municipal management. Quality of education. 


\section{REFERÊNCIAS}

BRASIL. Ministério do Planejamento, Orçamento e Gestão. Gestão de processos: um guia rápido orientado a resultados. Brasília: Ministério do Planejamento, 2009. Disponível em: 〈http://www.gespublica.gov.br/ferramentas/anexos/ guia_de_gestao_de_processos.pdf〉. Acesso em: 30 out. 2011.

CENPEC. O Programa Melhoria da Educação no Município e as políticas públicas sociais. São Paulo: Cenpec, 2009. (Coleção Diálogos sobre a Gestão Municipal, Caderno 1).

CENPEC; FUNDAÇÃO ITAÚ SOCIAL. Diálogos sobre a Gestão Municipal Processos na Educação. São Paulo: Cenpec, 2012. Disponível em: 〈http:// www.fundacaoitausocial.org.br/_arquivosestaticos/FIS/pdf/melhoria_ educacao_mun.pdf. Acesso em 13 abr. 2013.

FUNDACAO ITAÚ SOCIAL. Relatório de Avaliação Econômica do Programa Melhoria da Educação no Município. São Paulo: Fundação Itaú Social, 2007.

GONÇALVES, J. E. L.. As empresas são grandes coleções de processos. Revista de Administração de Empresas (RAE), São Paulo, v. 40, n.1, p.6-19, São Paulo, v. 40, n.1, p.6-19. jan./mar. 2000a.

Processo, que processo?, Revista de Administração de Empresas (RAE), São Paulo, v. 40, n.4, Out./Dez. 2000, São Paulo, v. 40, n.4, p. 8-19. out./dez. 2000 b.

IBGE (Instituto Brasileiro de Geografia e Estatística). Uma análise dos resultados do universo do Censo Demográfico 2010. Estudos e Pesquisas, Indicadores Sociais Municipais, Rio de Janeiro, n. 28, 2011.

LÜCK, H.; PARENTE, M. M. de A. Mapeamento da descentralização da educação brasileira nas redes estaduais do ensino fundamental. Rio de Janeiro: IPEA, 1999.

MINISTÉRIO DA EDUCAÇÃO. Apresentação. Disponível em 〈http://simec.mec. gov.br/cte/relatoriopublico/principal.php». Acesso em 10 Nov. 2012.

RECEBIDO: Janeiro de 2013.

APROVADO: Abril de 2013. 